\section{(2) OPEN ACCESS}

\title{
Efficacy of prolonged exposure therapy for a patient with late-onset PTSD affected by evacuation due to the Fukushima nuclear power plant accident
}

\author{
Arinobu Hori, ${ }^{1}$ Yoshitake Takebayashi, ${ }^{2}$ Masaharu Tsubokura, ${ }_{1}^{3}$ Yoshiharu $\mathrm{Kim}^{4}$
}

'Department of Psychiatry, Hori Mental Clinic, Minami-Soma, Fukushima, Japan

${ }^{2}$ Department of Health Risk Communication, School of Medicine, Fukushima Medical University, Fukushima, Japan ${ }^{3}$ Department of Public Health, School of Medicine, Fukushima Medical University, Fukushima Japan

${ }^{4}$ National Institute of Mental Health, National Center of Neurology and Psychiatry, Kodaira, Tokyo, Japan

Correspondence to

Dr Arinobu Hori;

arinobu.h@gmail.com

Accepted 15 December 2019

\section{SUMMARY}

Trauma-focused cognitive-behavioural therapy (TF-CBT), such as prolonged exposure therapy, is a first-line treatment for post-traumatic stress disorder (PTSD). However, adapting TF-CBT as an intervention in situations with limited resources, such as in disaster settings, is problematic. This case report concerns a Japanese man in his 30s who was diagnosed with lateonset PTSD 5 years after the 2011 Great East Japan Earthquake. The onset and progression of his symptoms were heavily affected by changes in his life after evacuation due to the postearthquake nuclear power plant accident. We were able to successfully implement structured CBT and help the patient better cope with his symptoms in a disaster-stricken location. CBT for PTSD includes exposure to traumatic memories, which may lead to worsening of PTSD symptoms, but we were able to administer the therapy successfully with clinical support through the use of modern information and communication technology.

\section{BACKGROUND}

It is not easy to implement trauma-focused cognitive-behavioural therapy (TF-CBT), including prolonged exposure (PE) therapy, ${ }^{1}$ as an intervention for post-traumatic stress disorder (PTSD) in situations where resources are scarce or unavailable, such as in postdisaster environments. CBT is recognised as the standard treatment for PTSD,${ }^{23}$ but such interventions are time-consuming and labour-intensive, and require therapists to have expertise in addressing patients' psychological pain stimulated by recollection of traumatic memories. This restricts the widespread application of CBT to victims immediately after a disaster. ${ }^{4}$ As a result, the use of psychological first aid (PFA), which avoids focusing on the traumatic experiences of disaster survivors and emphasises the importance of practical assistance, has been globally supported..$^{5-7}$ This is particularly so as critical incidence stress debriefing was found to be ineffective in the prevention of PTSD. ${ }^{8}$ Low-impact interventions, such as PFA, should be performed immediately after a disaster, and only when PTSD or depression symptoms persist for a certain period should a specialised treatment for each symptom, such as TF-CBT, be used. ${ }^{4}$ Therefore, the safety and efficacy of CBT for PTSD, which should be effective in disaster-hit areas, and the impact of including exposure techniques for traumatic memories need to be extensively examined.

Following the Great East Japan Earthquake (GEJE), subsequent tsunami and the resultant Fukushima nuclear power plant incident, PTSD became one of the most important issues for medical or administrative personnel striving to help disaster victims. The lifetime prevalence of PTSD in the Japanese population is $1.3 \% .^{10}$ However, 21.6\% of evacuees in 2011 and $18.3 \%$ in 2012 who had lived near the nuclear plant showed signs of PTSD, according to a self-administered questionnaire survey conducted by Fukushima Prefecture authorities and Fukushima Medical University. ${ }^{11}$ While the prevalence rate of PTSD after disasters often declines over time, ${ }^{12} 13$ it is also possible that the deterioration of survivors' living conditions could trigger late-onset PTSD. ${ }^{14}$ Therefore, it is important to develop effective intervention methods for patients with disasterrelated PTSD, both immediately following and in the months after the disaster.

We experienced a case of a male GEJE evacuee in his late 30s who presented with delayed PTSD. His life and living conditions after his evacuation deeply affected the course of his illness. By having a supervisor in Tokyo oversee the case via Skype, we were able to successfully administer PE therapy. ${ }^{1}$ PE therapy is a representative trauma-focused CBT which includes in vivo exposure to things that are usually avoided by patients and emotional processing through imaginal exposure to traumatic memories and psychoeducation. The implementation of PE therapy led to remission of the patient's PTSD symptoms. Even in the catastrophic conditions following natural or anthropogenic disasters, the use of modern information and communication technologies, such as Skype, facilitate the successful implementation of TF-CBT, as evidenced by our experience with PE therapy.

\section{CASE PRESENTATION}

The patient, a man in his late 30 s, first presented 5 years and 1 month after the GEJE. He was married and has two children. In 2011, he experienced the GEJE on a high pillar and in an area that was placed under compulsory evacuation. When he was relocated, he was able to engage in similar work as he was undertaking before the earthquake. Even though he suffered traumatic reactions such as 
nightmares immediately after the disaster, these reactions gradually decreased over time.

Three years after the earthquake, people were still being evacuated from a $20 \mathrm{~km}$ zone around the stricken nuclear plant. However, he decided to move to a new location that was deemed safe and which was closer to his original house. He got a new job, but the type of work was unfamiliar to him. He gradually realised that he could not "understand the work properly," and his work performance suffered significantly. He became severely anxious and depressed. Over the course of several months, he experienced panic attacks more frequently, along with feelings of irritability, insomnia and loss of appetite. The patient also described being in a traffic accident, crashing into another car that had stopped at an intersection, which worsened his various symptoms. He visited our clinic for the first time 2 months after the traffic accident.

At the first examination, it was determined that he had both PTSD and mood disorder symptoms; he was depressed and agitated. Treatment of the mood disorder symptoms was given priority. First, we prescribed antidepressants (clomipramine $100 \mathrm{mg}$ and mirtazapine $45 \mathrm{mg}$ ), which proved only partially effective, and his anxiety symptoms, including agitation, were not adequately controlled. His symptoms did not meet the criteria for hypomanic episodes, nor mixed feature ${ }^{2}$; however, there is a study pointing out that $40 \%-50 \%$ of individuals with major depressive disorder display lifetime subsyndromal hypomanic presentations that are not necessarily concurrent with a major depressive episode, and comorbid anxiety is a clinical confirmation of bipolarity. ${ }^{15}$ Additionally, based on a study reporting an increase in patients with bipolar disorder in Fukushima after the disaster, ${ }^{16}$ we prescribed lithium carbonate $400 \mathrm{mg}$. We decreased the dosage of clomipramine to $10 \mathrm{mg}$ and stopped administering mirtazapine. About 2 months after starting lithium carbonate, we were able to control his mood disorder symptoms. Subsequently, PTSD symptoms such as re-experience, avoidance and hyperarousal became evident. ${ }^{2}$

\section{DIFFERENTIAL DIAGNOSIS \\ Panic disorder}

When therapy started, he was experiencing panic attacks a few times a day. Therefore, panic disorder was considered a differential diagnosis. Later, after successfully completing PTSD treatment, his symptoms of panic attack also diminished.

\section{TREATMENT}

After consulting with the patient, we decided to implement PE therapy. ${ }^{1}$ There are several therapies effective for PTSD, with exposure therapy thought to be particularly efficacious. ${ }^{17}$ Securing a therapist was a challenge with respect to implementing PE in a disaster-stricken area as there was a scarcity of certified PE therapists ${ }^{1}$ at that time. However, we overcame the problem by recording the treatment scenarios of the actual case and asking a suitably qualified supervisor in Tokyo to oversee the therapy process via Skype, while one of us underwent a proper training course. Two courses of PE therapy were performed by the end of the treatment regimen.

The first course was carried out once a week for 6 weeks. This began 5 years and 3 months after the GEJE and 3 months after his first visit to our clinic. During the second session of the first course, he strongly emphasised his fear of not finding his children, stating: "could not find my children when I returned home soon after the earthquake. I felt a strong fear that my children would be smashed somewhere." This was despite the fact that he eventually found out his children were safe. Therefore, we repeatedly implemented imaginal exposure for that memory. After the first course was over, his condition stabilised.

Three months after the end of the first course, an earthquake with a seismic intensity of 5 occurred where the patient lived. The patient relapsed with depressive and anxiety symptoms, and these symptoms were resistant to pharmacotherapies. Therefore, we decided to conduct a second course of PE therapy. A total of six sessions were held once a week, now 6 years and 6 months after the GEJE and 1 year and 5 months after his first visit to our clinic. Even though he was extremely afraid to recall the bodily sensations caused by the earthquake he experienced on a high pillar, he could repeatedly recollect the traumatic memory during the therapeutic procedure.

After the second course of PE therapy, his symptoms had significantly improved, and he was able to continue to work without interruption and did not need to come to the clinic or take medications.

\section{OUTCOME AND FOLLOW-UP}

During the first course of PE therapy, a PTSD evaluation scalethe Posttraumatic Diagnostic Scale (PDS) ${ }^{18}$-was used. Before the first session, the patient scored 24 points, which decreased to 5 points after the sixth session. The Beck Depression Inventory Manual, Second Edition (BDI-II), ${ }^{19}$ which is a depression evaluation scale, was also used. He scored 30 points before the first session, which decreased to 5 points after the sixth session. $\mathrm{He}$ also subjectively reported "I felt more comfortable."

When the second course of PE therapy started, the PDS ${ }^{18}$ score was 17 points before the first session, decreasing to 4 points after the sixth session. The BDI-II ${ }^{19}$ score was 21 before the first session and fell to 11 points after the sixth session.

The patient's symptoms ameliorated after the administration of PE therapy for both courses, and the effects remained 1 year and 5 months after the treatment.

\section{DISCUSSION}

This case demonstrated that CBT treatment for PTSD is feasible in a setting with limited resources, such as after a disaster. In our case, the patient's PTSD symptoms, which had initially improved following a natural course soon after the disaster, recurred twice. The first recurrence was when he failed to adapt to a new workplace environment and was feeling anxious about the future. The second recurrence was when another earthquake happened and his sense of security was threatened. To carry out PE therapy for PTSD cases, it is essential that the patient's safety is secured. When he had work problems, he felt severe anxiety with regard to income; however, his family anticipated receiving some compensation from the Japanese government, his wife continued to support him, and family ties were kept strong.

There were two important factors responsible for the success of the therapy. One was that the patient felt safe and secure when the therapy was introduced, as described above. The other was that exposure to traumatic memories was conducted in a standardised and structured therapy process supported by scientific evidence. ${ }^{3}$ Even though medical resources available after disasters are often scarce, we were able to devise a therapy system through which PE therapy could be safely delivered, by using modern information and communication technology. We were able to successfully implement PE therapy in a PTSD case in a disaster-stricken area and the therapy was standardised. 
Because PE therapy for PTSD includes exposure to traumatic memories, there is a risk that patients will experience intense pain and face relapse of PTSD symptoms, especially when the patient's daily life is not stable and open to continuous stress factors. However, advances in information technology have made it easier to implement CBT even in circumstances where healthcare provision of all kinds is problematic and uncertain. The current case suggests that implementing CBT safely, such as PE therapy, for postdisaster PTSD is possible during the chronic phase and that it is effective in ameliorating PTSD symptoms.

\section{Learning points}

- Post-traumatic stress disorder (PTSD) symptoms can recur even several years after a disaster due to perturbation and disruption in and deterioration of the living environment of a patient.

- Clinicians should try to implement evidence-based effective treatments, such as trauma-focused cognitive-behavioural therapy for PTSD, even in extremely disadvantageous and difficult circumstances.

- To carry out prolonged exposure therapy, including repeated exposure to traumatic memories, there are two essential conditions: one is that the patient should feel safe in his/ her daily life and the other is that the treatment should be properly structured and standardised.

Contributors $\mathrm{AH}$ was the main therapist of the case and wrote the initial manuscript. YT was the cotherapist of the case. MT critically revised the manuscript. YK supervised the case. All authors contributed to the refinement of the paper and approved the final manuscript.

Funding The authors have not declared a specific grant for this research from any funding agency in the public, commercial or not-for-profit sectors.

Competing interests None declared.

Patient consent for publication Obtained.

Provenance and peer review Not commissioned; externally peer reviewed.

Open access This is an open access article distributed in accordance with the Creative Commons Attribution Non Commercial (CC BY-NC 4.0) license, which permits others to distribute, remix, adapt, build upon this work non-commercially, and license their derivative works on different terms, provided the original work is properly cited and the use is non-commercial. See: http://creativecommons.org/ licenses/by-nc/4.0/.

\section{REFERENCES}

1 Foa EB, Kozak MJ. Emotional processing of fear: exposure to corrective information. Psychol Bull 1986:99:20-35.

2 American Psychiatric Association. Diagnostic and statistical manual of mental disorders, fifth edition (DSM-5). Arlington, VA: American Psychiatric Publishing, 2013.

3 Lee DJ, Schnitzlein CW, Wolf JP, et al. Psychotherapy versus pharmacotherapy for posttraumatic stress disorder: systemic review and meta-analyses to determine firstline treatments. Depress Anxiety 2016;33:792-806.

4 North CS, Pfefferbaum B. Mental health response to community disasters: a systematic review. JAMA 2013:310:507-18.

5 World Health Organization. Psychological first aid: guide for field workers [Internet]. Available: http://www.who.int/mental_health/publications/guide_field_workers/en/ [Accessed 21 Jul 2019].

6 National Child Traumatic Stress Network/National Center for PTSD. Psychological first aid: field operations guide. Available: http://www.nctsn.org/content/psychologicalfirst-aid [Accessed 21 Jul 2019].

7 Stoddard FJ, Pandya A, Katz CL. Psychological first aid. In: Stoddard FJ, Pandya A, Katz $\mathrm{CL}$, eds. Disaster psychiatry: readiness, evaluation, and treatment. Washington DC: American Psychiatric Publishing, 2012.

8 Mitchell JT. When disaster strikes....the critical incident stress debriefing process. JEMS 1983:8:36-9.

9 Kagee A. Concerns about the effectiveness of critical incident stress debriefing in ameliorating stress reactions. Crit Care 2002;6.

10 Kawakami N, Tsuchiya M, Umeda M, et al. Trauma and posttraumatic stress disorder in Japan: results from the world mental health Japan survey. J Psychiatr Res 2014;53:157-65.

11 Yabe H, Suzuki Y, Mashiko H, et al. Psychological distress after the great East Japan earthquake and Fukushima Daiichi nuclear power plant accident: results of a menta health and lifestyle survey through the Fukushima health management survey in FY2011 and FY2012. Fukushima J Med Sci 2014:60:57-67.

12 Guo J, Wu P, Tian D, et al. Post-Traumatic stress disorder among adult survivors of the Wenchuan earthquake in China: a repeated cross-sectional study. J Anxiety Disord 2014;28:75-82.

13 Cénat JM, Derivois D. Assessment of prevalence and determinants of posttraumatic stress disorder and depression symptoms in adults survivors of earthquake in Haiti after 30 months. J Affect Disord 2014:159:111-7.

14 Pietrzak RH, Van Ness PH, Fried TR, et al. Trajectories of posttraumatic stress symptomatology in older persons affected by a large-magnitude disaster. J Psychiatr Res 2013:47:520-6.

15 Nusslock R, Frank E. Subthreshold bipolarity: diagnostic issues and challenges. Bipolar Disord 2011:13:587-603.

16 Matsumoto J, Kunii Y, Wada A, et al. Mental disorders that exacerbated due to the Fukushima disaster, a complex radioactive contamination disaster. Psychiatry Clin Neurosci 2014;68:182-7.

17 Cusack K, Jonas DE, Forneris CA, et al. Psychological treatments for adults with posttraumatic stress disorder: a systematic review and meta-analysis. Clin Psychol Rev 2016:43:128-41.

18 Foa EB, Cashman L, Jaycox L, et al. The validation of a self-report measure of posttraumatic stress disorder: the posttraumatic diagnostic scale. Psychol Assess 1997:9:445-51.

19 Beck AT, Steer RA, Brown GK. BDI-II: Beck depression inventory manual. 2nd edn. San Antonio, TX: Psychological Corporation, 1996.

Copyright 2019 BMJ Publishing Group. All rights reserved. For permission to reuse any of this content visit

https://www.bmj.com/company/products-services/rights-and-licensing/permissions/

BMJ Case Report Fellows may re-use this article for personal use and teaching without any further permission.

Become a Fellow of BMJ Case Reports today and you can:

- Submit as many cases as you like

Enjoy fast sympathetic peer review and rapid publication of accepted articles

- Access all the published articles

Re-use any of the published material for personal use and teaching without further permission

Customer Service

If you have any further queries about your subscription, please contact our customer services team on +44 (0) 2071111105 or via email at support@bmj.com.

Visit casereports.bmj.com for more articles like this and to become a Fellow 